\title{
ОСТЕОАРТРОЗ КОЛЕННОГО СУСТАВА У ПОЖИЛЫХ - ВСЕГДА ЛИ ОПРАВДАНО ЭНДОПРОТЕЗИРОВАНИЕ?
}

\author{
А. В. Лычагин, А. В. Гаркави
}

Лечебный факультет, Первый московский государственный медицинский университет имени И. М. Сеченова (Сеченовский Университет), Москва, Россия

\begin{abstract}
Остеоартроз - заболевание преимущественно пожилых людей, и по локализации первое место уверенно удерживает коленный сустав. Именно в пожилом и старческом возрасте возможность активного лечения пациентов с гонартрозом ограничена их полиморбидностью, а также повышенным операционным риском. Поэтому весьма актуален поиск методик лечения, способных хотя бы на время стать альтернативой эндопротезированию коленного сустава. Целью исследования было проанализировать оправданность операции эндопротезирования коленного сустава у пациентов пожилого и старческого возраста с гонартрозом и разработать комплексную систему лечения, сохраняющую сустав. В исследовании участвовали 178 пациентов старше 60 лет, которым ранее было предложено, но не выполнено эндопротезирование коленного сустава по поводу верифицированного гонартроза. Для определения лечебной тактики использовали оригинальную балльную систему оценки дислокационного синдрома коленного сустава. Применяли сочетание санационной артроскопии с внутрисуставным введением гиалуроновой кислоты и обогащенной тромбоцитами аутоплазмы (РRP). Для анализа результатов определяли статистическую значимость отмеченных отличий по стандартному пакету программ «Statistica 12.0». Показано, что 39,3\% пациентов эндопротезирование было предложено без достаточных объективных оснований. Проведение комплексного лечения, сочетающего внутрисуставную PRP-терапию с предварительно проведенной санационной артроскопией, стало альтернативой эндопротезированию для всех пациентов как минимум на год, а внутрисуставная терапия без артроскопии — только для 40\%.
\end{abstract}

Ключевые слова: эндопротезирование коленного сустава, артроскопия, внутрисуставная инъекционная терапия

Информация о вкладе авторов: А. В. Лычагин - создание шкалы оценки степени ДСКС, планирование исследования, выполнение операций артроскопии, послеоперационное наблюдение, систематизация и анализ результатов; А. В. Гаркави - планирование и создание дизайна исследования, операции артроскопии, внутрисуставные инъекции, наблюдение пациентов в динамике, систематизация и анализ результатов, оформление статьи; В. А. Мещеряков - артроскопия, внутрисуставные инъекции, наблюдение и анкетирование пациентов; В. С. Кайков - артроскопия, внутрисуставные инъекции, наблюдение и анкетирование пациентов.

Соблюдение этических стандартов: исследование одобрено этическим комитетом ФГАОУ ВО Первый МГМУ им. И. М. Сеченова (протокол № 17-18, 2018 г.); все пациенты подписали добровольное информированное согласие на участие в проводимом исследовании.

$凶$ Для корреспонденции: Андрей Владимирович Гаркави

ул. Трубецкая, д. 8, стр. 2, г. Москва, 119991; Avgar22@yandex.ru

Статья получена: 13.09.2018 Статья принята к печати: 25.03.2019 Опубликована онлайн: 06.04.2019

DOI: $10.24075 /$ vrgmu.2019.020

\section{OSTEOARTHRITIS OF THE KNEE IN THE ELDERLY: IS KNEE REPLACEMENT ALWAYS JUSTIFIED?}

Lychagin AV, Garkavi AV $\bowtie$, Meshcheryakov VA, Kaykov VS

Faculty of General Medicine, I. M. Sechenov First Moscow State Medical University, Moscow, Russia

Osteoarthritis is a condition that mostly affects the elderly population and tends to be localized to the knee joint. At old age, active treatment options are limited by co-morbidities and a higher risk for surgical complications. Therefore, the search for strategies that could become a temporary alternative to knee replacement is a pressing concern. The aim of this study was to analyze how justifiable is total knee replacement in elderly patients with knee osteoarthritis and to propose a less aggressive therapeutic alternative to this surgery. The study included 178 patients over 60 years of age with clinically established knee osteoarthritis who had been previously recommended knee replacement but chosen not to undergo it. The choice of a treatment strategy tested in the study was based on the original grading scale for the evaluation of the knee joint dislocation syndrome. The treatment consisted of therapeutic arthroscopy and intraarticular injections of hyaluronic acid and platelet-rich plasma (PRP). The data were processed in Statistica 12. Data analysis revealed that 39.3\% of the participants did not have compelling indications for knee replacement. The proposed combination therapy with intraarticular PRP injections and arthroscopy allowed all the patients to delay knee replacement for at least a year; unaided by arthroscopy, intraarticular injections worked well for only $40 \%$.

Keywords: knee arthroplasty, total knee replacement, arthroscopy of the knee, intraarticular injection

Author contribution: Lychagin AV devised a KJDS scale, planned the study, performed arthroscopy and follow-up observation, processed and analyzed the data. Garkavi AV planned the study and proposed its design, performed arthroscopy, intraarticular injections and follow-up observation, processed and analyzed the data, and wrote the manuscript. Meshcheryakov VA performed arthroscopy, intraarticular injections and follow-up observation, surveyed the patients. Kaykov VS performed arthroscopy, intraarticular injections, and follow-up observation, surveyed the patients.

Compliance with ethical standards: this study was approved by the Ethics Committee of I. M. Sechenov First Moscow State Medical University (Protocol No. 17-18 dated 2018); the patients gave informed consent to participate.

Correspondence should be addressed: Andrey V. Garkavi Trubetskaya 8, bld. 2, Moscow, 119991; Avgar22@yandex.ru

Received: 13.09.2018 Accepted: 25.03.2019 Published online: 06.04.2019

DOI: 10.24075/brsmu.2019.020

Остеоартроз коленного сустава, являясь одним из наиболее распространенных ортопедических заболеваний, практически всегда сопровождается болевым синдромом и дисфункцией, что снижает качество жизни, поскольку может привести к значительному уменьшению физической активности и инвалидности. Наиболее характерен остеоартроз для лиц пожилого возраста. У таких пациентов он особенно часто служит причиной ограничений возможности самообслуживания, социальной дезадаптации, депрессии [1-5].

С одной стороны, на фоне выраженных инволютивных изменений консервативное лечение пациентов пожилого и старческого возраста с гонартрозом преследует 
достижение только относительно непродолжительного паллиативного эффекта. С другой стороны, постоянно совершенствуются возможности артропластики, благодаря чему эндопротезирование становится все менее травматичным, более доступным и безопасным [6-12].

В связи с этим в последние годы наметилась тенденция к росту количества эндопротезирований коленного сустава у пожилых, так как показания к таким операциям стали существенно шире [13-15]. Однако в ряде случаев самого диагноза гонартроза в сочетании с преклонным возрастом достаточно, чтобы, не предпринимая попыток лечения менее агрессивными способами (артроскопия, внутрисуставная и системная фармакотерапия, реабилитационное лечение), рассматривать эндопротезирование как единственную возможность получения положительного результата. Но не лишаем ли мы пациентов шансов избежать операции все же связанной, несмотря на прогресс медицины, с определенным операционным риском и возможными осложнениями $[16,17]$ ?

К сожалению, отсутствие на данный момент единого универсального подхода к определению показаний к эндопротезированию коленного сустава не позволяет считать все полученные нашими пациентами в других лечебных учреждениях рекомендации по замене пораженного коленного сустава в достаточной степени объективными и обоснованными.

Целью исследования было проанализировать оправданность операции тотального эндопротезирования коленного сустава (ТЭКС) и разработать методику альтернативного лечения.

\section{ПАЦИЕНТЫ И МЕТОДЫ}

Под нашим наблюдением находилось 178 пациентов нетрудоспособного возраста в возрасте 60-82 лет, которым ранее была предложена операция ТЭКС, однако по различным причинам (от отказа пациента из-за страха перед предложенной операцией до необходимости ожидания очереди на госпитализацию) эндопротезирование им выполнено не было. Эти пациенть согласились пройти курс предложенного лечения и затем вернуться к обсуждению вопроса о необходимости выполнения ТЭКС. Критерии включения в исследование: возраст пациентов 60 лет и старше; наличие установленного ранее диагноза «гонартроз» с рекомендацией эндопротезирования коленного сустава; наличие подписанного информированного согласия пациентов пройти курс комплексного лечения по разработанной нами схеме с последующим наблюдением в течение года. Критерии исключения: наличие тяжелых сопутствующих соматических заболеваний, существенно ограничивающих возможность самостоятельной ходьбы и являющихся противопоказанием к используемым методам лечения; наличие последствий внутрисуставного перелома области коленного сустава с сохраняющейся дисконгруентностью суставных поверхностей; неспособность к осознанному конструктивному сотрудничеству.

В ходе обследования устанавливали степень дислокационного синдрома коленного сустава (ДСКС) по методике А. В. Лычагина [18], согласно которой оценивали пять параметров: состояние суставного хряща, состояние

Таблица 1. Оценка степени дислокационного синдрома коленного сустава (в баллах)

\begin{tabular}{|c|c|c|}
\hline Анатомо-функциональные нарушения & Характер патологии & Оценка (баллы) \\
\hline \multirow{5}{*}{$\begin{array}{l}\text { Состояние суставного хряща (по классификации ICRS) } \\
\text { по данным магнитно-резонансной томографии } \\
\text { или артроскопии }\end{array}$} & норма & 0 \\
\hline & 1-2-я степень & 1 \\
\hline & 3-я степень & 2 \\
\hline & 4-я степень с небольшим дефектом (до 2,5см²) & 3 \\
\hline & 4-я степень со значительным дефектом (> 2,5 см²) & 4 \\
\hline \multirow{5}{*}{ Состояние кости в параартикулярной зоне } & - норма & 0 \\
\hline & - остеопороз & 1 \\
\hline & - кисты & 2 \\
\hline & - импрессия незначительная & 3 \\
\hline & - импрессия выраженная & 4 \\
\hline \multirow{5}{*}{ Нестабильность } & Нет & 0 \\
\hline & Компенсированная (1 степень) & 1 \\
\hline & Субкомпенсированная (2 степень) & 2 \\
\hline & Декомпенсированная (3 степень) & 3 \\
\hline & Артрогенные контрактуры & 4 \\
\hline \multirow{5}{*}{ Сужение суставной щели (\%) } & $0-5$ & 0 \\
\hline & $6-30$ & 1 \\
\hline & $31-50$ & 2 \\
\hline & $51-75$ & 3 \\
\hline & $76-100$ & 4 \\
\hline \multirow{5}{*}{ Шкала оценки WOMAC (баллы) } & Ниже 30 & 0 \\
\hline & $31-50$ & 1 \\
\hline & $51-70$ & 2 \\
\hline & $71-90$ & 3 \\
\hline & Выше 90 & 4 \\
\hline
\end{tabular}


кости в параартикулярной зоне, степень нестабильности, сужение суставной щели и сумму баллов по WOMAC. Каждому параметру присваивали от 0 до 4 баллов, таким образом максимально возможная сумма баллов (абсолютно неблагоприятный прогноз) составляла 20.

Сумма баллов по этой шкале, равная 0-5, означает возможность проведения эффективной консервативной фармакотерапии, 6-12 баллов - возможность успешного комплексного лечения с применением артроскопии и Внутрисуставной инъекционной терапии, и только ДСКС в диапазоне 13-20 баллов считается показанием к выполнению ТЭКС.

Из 178 пациентов с гонартрозом II-III степени (по классификации Kellgren-Lawrence), которым ранее было предложено ТЭКС, имели подтвержденные по данной методике оценки показания к этой операции (от 13 баллов и выше) только 108 (60,7\%) (рис. 1).

Пациенты были разделены на три группы. В 1-й группе (54 человека) в ходе лечения проводили внутрисуставные инъекции обогащенной тромбоцитами аутоплазмы (PRPтерапия), во 2-й группе (64 человека) - внутрисуставные инъекции гиалуроновой кислоты. Пациенты 3-й группы получали системную фармакотерапию (хондропротекторы и НПВС).

У 118 пациентов, у которых в качестве первого этапа комплексного лечения была включена санационная

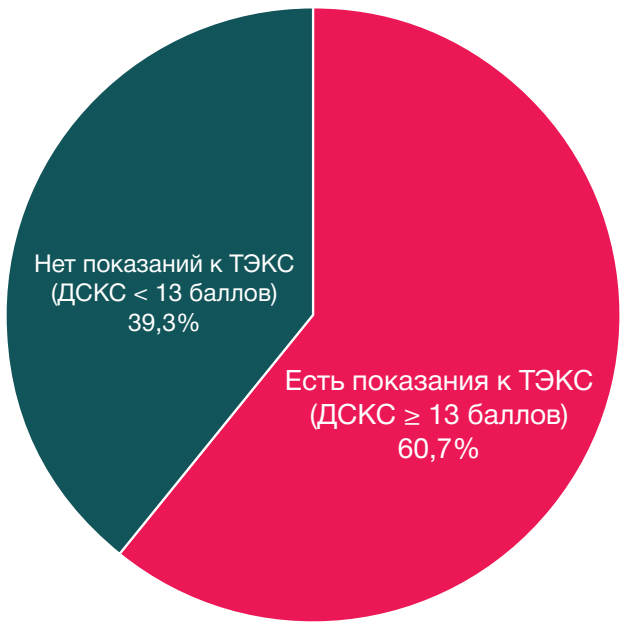

Рис. 1. Показания к операции, определенные на основании оценки ДСКС у пациентов, которым было предложено ТЭКС артроскопия, ДСКС был оценен в 6 и более баллов: в 1-й группе - у 32 (59,3\%) пациентов, во 2-й - у 44 (68,8\%) и в 3-й - у 42 (70,0\%) (рис. 2).

\section{РЕЗУЛЬТАТЫ ИССЛЕДОВАНИЯ}

При оценке результатов проведенного лечения пациентов следует разделить по степени тяжести остеоартроза. В качестве такого критерия была выбрана не рентгенологическая оценка остеоартроза, которая, как известно, не всегда коррелирует с выраженностью жалоб пациента и снижением качества жизни, а шкала оценки степени ДСКС, позволяющая сделать вывод о наличии или отсутствии объективных показаний к эндопротезированию. Как уже упоминалось, из 178 пациентов, которым ранее было предложено ТЭКС, у 70, согласно данной шкале, такие объективные показания отсутствовали (табл. 2).

Эти наблюдения говорят не о полном и окончательном отказе от возможного эндопротезирования коленного сустава, а лишь о том, что как минимум на год пациент удовлетворен результатом лечения и не рассматривает возможность выполнения ТЭКС в ближайшем будущем.

Из 70 пациентов, которым ранее было предложено ТЭКС, по нашей оценке, без достаточных оснований (ДСКС < 13 баллов), после проведенного курса лечения продолжали рассматривать этот вопрос лишь 15 человек

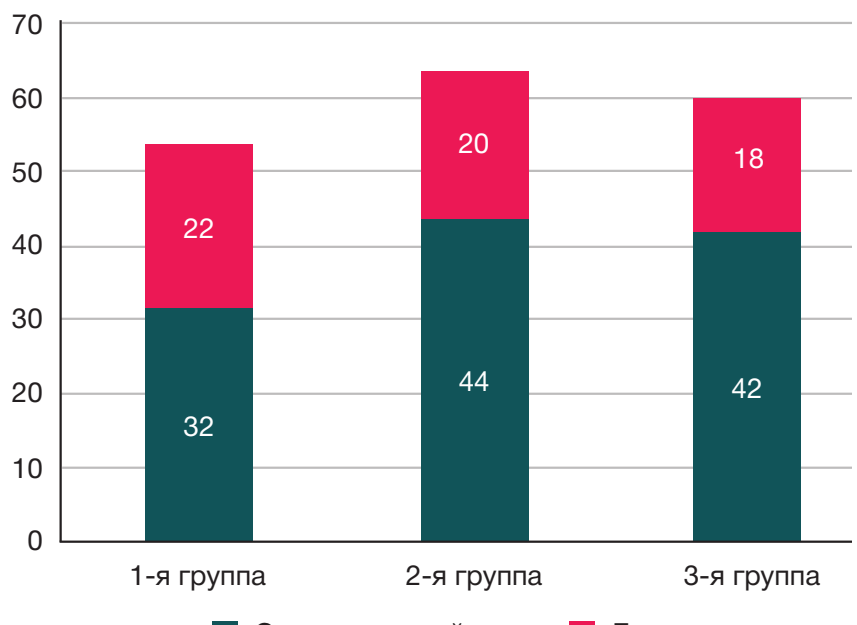

С артроскопией

Без артроскопии

Рис. 2. Включение санационной артроскопии в комплекс лечения

Таблица 2. Отношение пациентов к предложенному ТЭКС через год после проведенного лечения

\begin{tabular}{|c|c|c|c|c|c|c|}
\hline & \multirow{2}{*}{\multicolumn{2}{|c|}{$\begin{array}{c}\text { Количество пациентов, согласившихся на } \\
\text { проведение комплексного лечения вместо } \\
\text { ранее предложенного ТЭКС }\end{array}$}} & \multicolumn{2}{|c|}{$\begin{array}{c}\text { Количество пациентов, которым } \\
\text { выполнили санационную артроскопию }\end{array}$} & \multicolumn{2}{|c|}{$\begin{array}{c}\text { Количество пациентов, которым } \\
\text { не выполнили санационную артроскопию }\end{array}$} \\
\hline & & & \multirow{2}{*}{$\begin{array}{c}\text { Всего } \\
5\end{array}$} & \multirow{2}{*}{$\begin{array}{c}\text { Из них готовы обсуждать } \\
\text { возможность выполнения ТЭКС } \\
\text { после проведенного лечения } \\
0\end{array}$} & \multirow{2}{*}{$\begin{array}{c}\text { Всего } \\
13\end{array}$} & \multirow{2}{*}{$\begin{array}{c}\text { Из них готовы обсуждать } \\
\text { возможность выполнения ТЭКС } \\
\text { после проведенного лечения } \\
0\end{array}$} \\
\hline 1-я группа & $\begin{array}{l}\text { ТЭКС предложено } \\
\text { без достаточных оснований }\end{array}$ & 18 & & & & \\
\hline & Предложение ТЭКС обосновано & 36 & 27 & 0 & 9 & $5(55,6 \%)$ \\
\hline \multirow{2}{*}{$\begin{array}{l}\text { 2-я группа } \\
(n=64)\end{array}$} & $\begin{array}{l}\text { ТЭКС предложено } \\
\text { без достаточных оснований }\end{array}$ & 24 & 15 & 0 & 9 & $2(22,2 \%)$ \\
\hline & Предложение ТЭКС обосновано & 40 & 29 & $2(6,9 \%)$ & 11 & $7(63,6 \%)$ \\
\hline \multirow{2}{*}{$\begin{array}{l}\text { 3-я группа } \\
(n=60)\end{array}$} & $\begin{array}{l}\text { ТЭКС предложено } \\
\text { без достаточных оснований }\end{array}$ & 28 & 13 & $4(30,8 \%)$ & 15 & $9(60,0 \%)$ \\
\hline & Предложение ТЭКС обосновано & 32 & 29 & $22(75,9 \%)$ & 3 & $3(100 \%)$ \\
\hline \multirow{2}{*}{$\begin{array}{l}\text { Всего } \\
(n=178)\end{array}$} & $\begin{array}{l}\text { ТЭКС предложено } \\
\text { без достаточных оснований }\end{array}$ & 70 & 33 & $4(12,1 \%)$ & 37 & $11(29,7 \%)$ \\
\hline & Предложение ТЭКС обосновано & 108 & 85 & $24(28,2 \%)$ & 23 & $15(65,2 \%)$ \\
\hline
\end{tabular}


(21,4\%), причем в основном это были пациенты 3-й группы, которым не проводили внутрисуставную инъекционную терапию (13 человек из 28, или 46,4\%), тогда как в 1-й группе отказались от эндопротезирования все пациенты (100\%), а во 2-й группе - 22 человека из 24 (91,7\%) (рис. 3).

Из 108 человек с более тяжелыми поражениями суставов и объективными показаниями к ТЭКС (ДСКС $\geq$ 13 баллов) после проведенного курса лечения продолжали рассматривать этот вопрос 39 человек (36,1\%), следовательно, можно предположить значительное субъективное улучшение состояния у остальных 69 человек (63,9\% ) (рис. 4).

В наибольшей степени проведенное лечение явилось альтернативой эндопротезированию у пациентов, которым проводили внутрисуставную инъекционную терапию: в 1-й группе - у 86,1\%, во 2-й - у 77,5\%. В то же время в 3-й группе, несмотря на то что у 90,6\% пациентов была выполнена санационная артроскопия, 25 человек из 32 (78,1\%) продолжали рассматривать возможность ТЭКС, так как не были удовлетворены достигнутым результатом.

\section{ОБСУЖДЕНИЕ РЕЗУЛЬТАТОВ}

Эффеективность проводимой внутрисуставной инъекционной терапии и выполненной в начале лечения санационной артроскопии можно оценивать как по отдельности, так и в комплексе.

Если оценивать результаты опроса с позиций оценки эффективности проведенной внутрисуставной терапии, то из 118 пациентов (в совокупности 1-й и 2-й групп), ранее рассматривавших возможность проведения предложенной им операции ТЭКС, в 42 случаях операция была рекомендована без достаточных оснований, и после данного курса лечения, включающего внутрисуставные инъекции PRP или гиалуроновой кислоты, только двое $(4,8 \%)$ продолжали рассматривать возможность выполнения ТЭКС. В 3-й группе, где внутрисуставную терапию не проводили, таких наблюдений было 13 из 28 (46,4\%).

По подтвержденным в ходе нашего обследования объективным показаниям ТЭКС было ранее предложено 76 пациентам (совокупно 1-й и 2-й групп), им в ходе комплексного лечения проводили внутрисуставные инъекции. Из них к концу наблюдения продолжали рассматривать возможность ТЭКС 14 человек (18,4\%).

Если анализировать результаты этого опроса с позиций оценки влияния выполненной в начале лечения

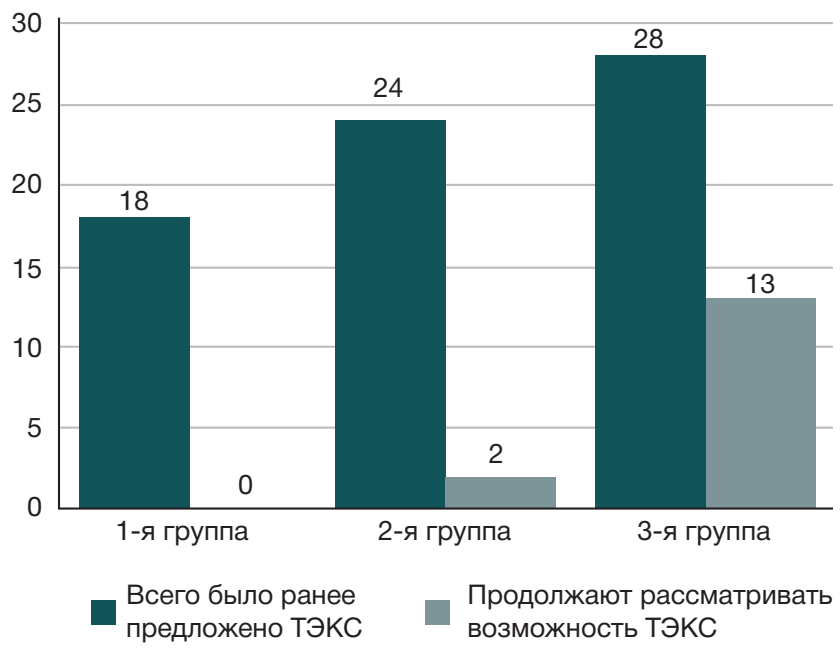

Рис. 3. Отношение после проведенного лечения к ТЭКС пациентов, которым эндопротезирование было предложено без достаточных оснований санационной артроскопии, то в 1-й группе из 54 пациентов артроскопия выполнена у 32, и никто из них через год не изъявил желания обсуждать вопрос о ТЭКС в ближайшем будущем (0\%). Во 2-й группе из 64 пациентов санационная артроскопия выполнена в 44 наблюдениях, и только в 2 случаях (4,5\%) операция ТЭКС не была снята с повестки дня. В 3-й группе у 60 пациентов выполнено 42 операции артроскопии и обсуждать возможность ТЭКС через год были готовы 18 человек (42,9\%), тогда как без артроскопии таких пациентов было 14 из 18 (77,8\%) (табл. 2).

При отсутствии достаточных оснований к ТЭКС проведенная терапия ожидаемо значительно чаще оказалась альтернативой эндопротезированию. После выполненной артроскопии таких пациентов было 29 из 33 (87,9\%), причем в 1-й и 2-й группах эта доля составила 100\%. Из 48 пациентов, которым артроскопию не выполняли, отсрочить или избежать ТЭКС удалось в 37 случаях $(77,1 \%)$ - в 1-й группе доля таких случаев составила $100 \%$, во 2-й - 81,8\%, в 3-й - 62,5\% (рис. 5).

Из пациентов, которым ТЭКС было объективно показано, после выполненной артроскопии отказались от эндопротезирования 71,7\% (61 человек из 85), причем в 1-й группе - 100\%, во 2-й - 93,1\%, а в 3-й - только 24,1\%, что еще раз подтверждает эффективность проводимой внутрисуставной терапии и прежде всего PRP в комплексном лечении остеоартрозов коленного сустава. Не выполняли артроскопию 23 пациентам, которым объективно было показано ТЭКС. Из них только у 8 (34,8\%) человек проведенное лечение явилось временной альтернативой ТЭКС, и все они относятся к пациентам, которым проводили внутрисуставную инъекционную терапию: в 1-й группе - 4 из 9 наблюдений (44,4\%), во 2-й группе - 4 из 11 случаев (36,4\%) (рис. 6).

\section{ВЫВОДЫ}

1. Показания к эндопротезированию коленного сустава в ряде случаев определяются без достаточных оснований, особенно у пожилых пациентов, что приводит к избыточно активной тактике. Применение в наших наблюдениях системы оценки, основанной на степени ДСКС (по методике А. В. Лычагина), показало обоснованность предложенного эндопротезирования лишь в 60,7\% наблюдений. 2. Комплексное лечение пожилых

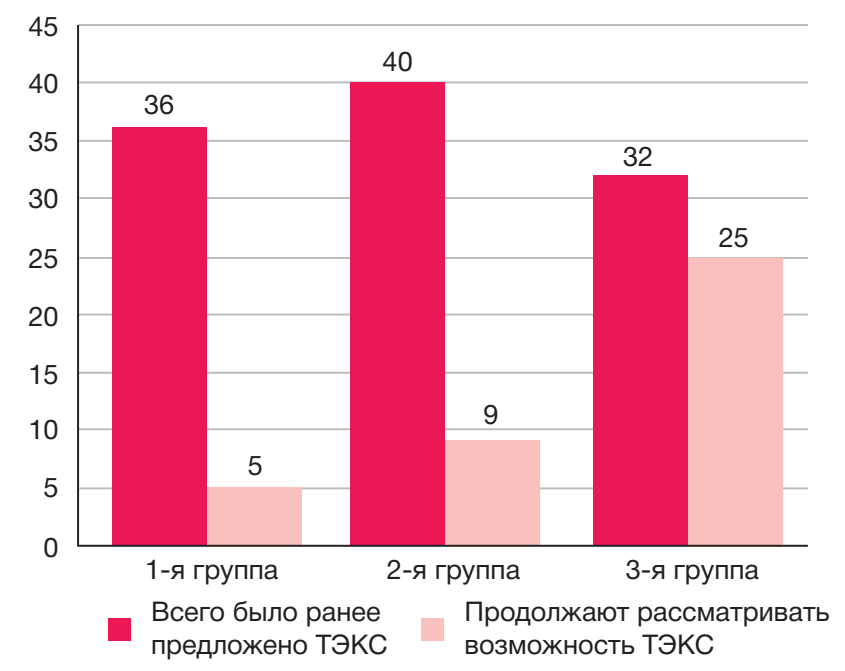

Рис. 4. Отношение после проведенного лечения к ТЭКС пациентов, которым эндопротезирование было предложено по объективным показаниям 
После артроскопии

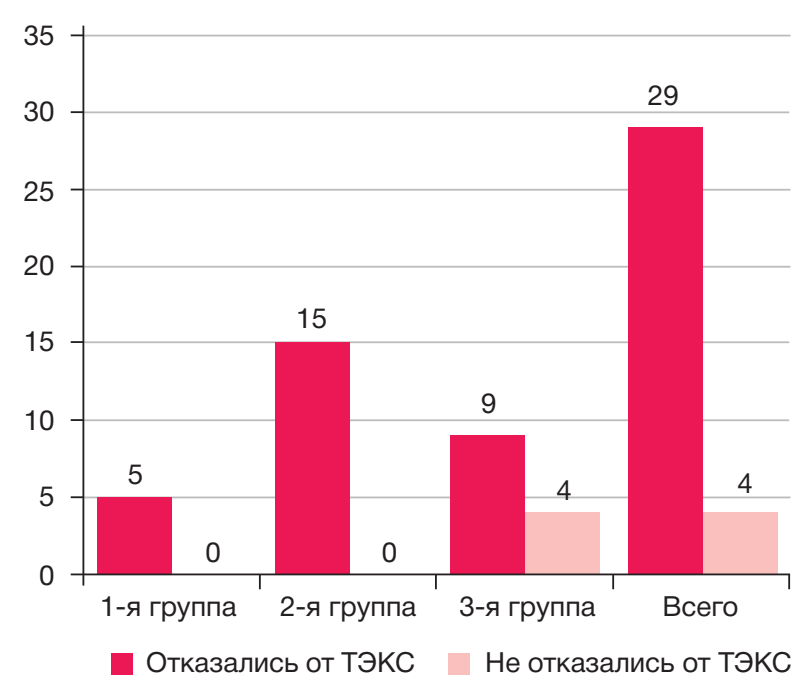

Без артроскопии

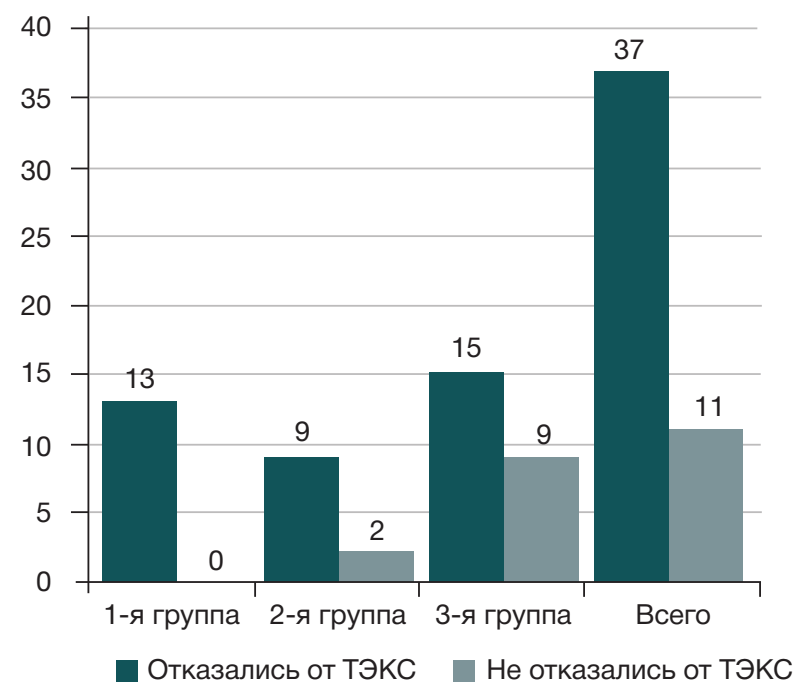

Рис. 5. Влияние артроскопии на отношение к ТЭКС пациентов, которым эндопротезирование было предложено без достаточных оснований

После артроскопии

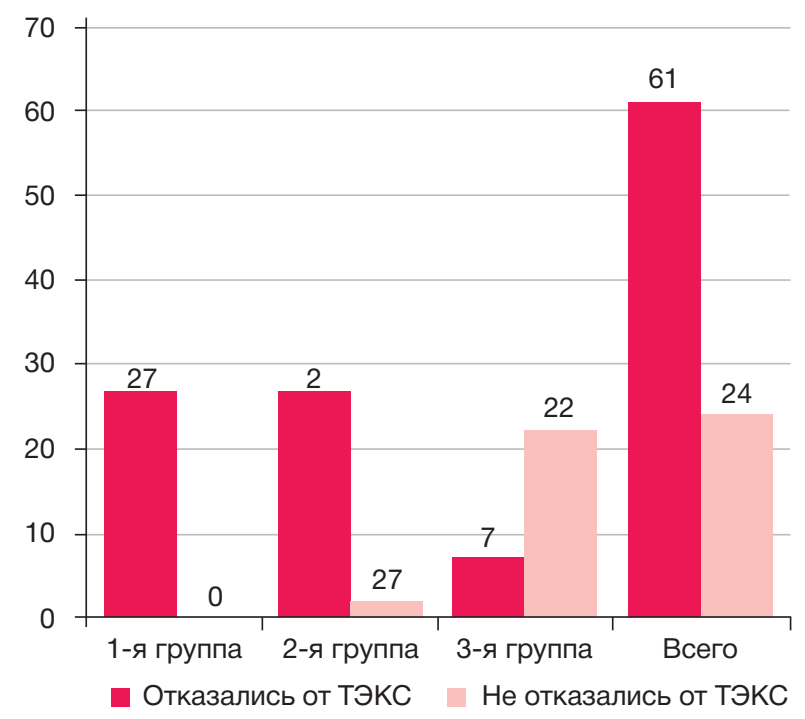

Без артроскопии

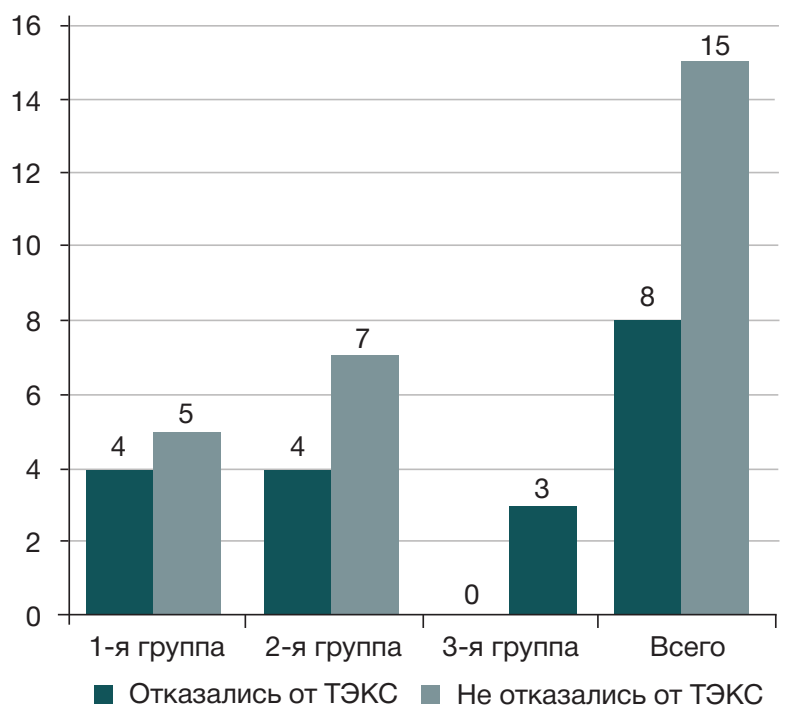

Рис. 6. Влияние артроскопии на отношение к ТЭКС пациентов, которым эндопротезирование было предложено по объективным показаниям

пациентов с гонартрозом, сочетающее санационную артроскопию с внутрисуставной PRP-терапией, может служить как минимум в течение года альтернативой эндопротезированию. 3. Внутрисуставная терапия без предварительной санационной артроскопии может служить альтернативой эндопротезированию коленного сустава при наличии объективных показаний к этой операции у 40,0\% пациентов.

\section{Литература}

1. Брагина С. В., Матвеев Р. П. Структура стойкой утраты трудоспособности у пациентов с гонартрозом. Гений ортопедии. 2011; (4): 96-100.

2. Савелова Е. Е., Майко О. Ю. Качество жизни больных гонартрозом по анкете ЕР-50. В сборнике: Материалы II Всероссийского конгресса ревматологов России; 26-29 апреля; Ярославль, 2011 г.; 68.

3. Хамроева З. Д. Оценка клинического течения и особенностей лечения остеоартроза у лиц пожилого и старческого возраста [диссертация]. Душанбе, 2016.

4. Цурко В. В., Егоров И. В., Красносельский М. Я. Суставной синдром у пожилых: Патофизиология боли и клинико-возрастные аспекты терапии. Consilium Medicum. 2009; 11 (2): 2-10.

5. Шукурова С. М., Хамроева З. Д., Шодиев Б. Р., Каримова Г. Н.

Остеоартроз как важная проблема гериатрии. Вестник Авиценны. 2015; (1): 137-43.

6. Vignon E, Valat JP, Rossignol M, et al. Osteoarthritis of the knee and hip and activity: a systematic international review and synthesis (OASIS). Joint Bone Spine. 2006; (73): 442-55.

7. Алексеева Л. И., Цветкова Е. С. Остеоартроз: из прошлого в будущее. Научно-практическая ревматология. 2009; (2): 31-39.

8. Батпенов Н. Д., Баймагамбетов Ш. А. и др. Артроскопия коленного сустава при остеоартрозе коленного сустава. В сборнике: Материалы VII Конгресса Российского артроскопического общества; 17-19 декабря 2007 г.; Москва. M.: 49.

9. Дубров В. Э., Ярема И.В., Ребров В. Н. Комплексное лечение дегенеративно-воспалительных поражений коленного сустава 
у пожилых больных. Травматология и ортопедия России. 2005; (35): 49

10. Заболотных И. И., Заболотных В. А. Болезни суставов в пожилом возрасте. СПб.: Петрополис, 2000; 144 с.

11. Каратеев Д. Е. Фармакотерапия остеоартроза: эсффективность и безопасность. Поликлиника. 2010; (5): 74-9.

12. Sinusas K. Osteoarthritis: diagnosis and treatment. Am Fam Physician. 2012; 85 (1): 49-56.

13. Кавалерский Г. М., Лычагин А. В., Сметанин С. М. и др. Историческое развитие концепции эндопротезирования коленного сустава. Кафедра травматологии и ортопедии. 2016; (3): 16-20.

14. Тарбушкин А. А. Оценка структурно-функциональных нарушений коленного сустава для определения показания к

\section{References}

1. Bragina SV, Matveev RP. Struktura stojkoj utraty trudosposobnost u pacientov s gonartrozom. Genij ortopedii. 2011; (4): 96-100.

2. Savelova EE, Majko OYu. Kachestvo zhizni bol'nyh gonartrozom po ankete ER-50. Materialy II Vserossijskogo kongressa revmatologov Rossii. Yaroslavl', $2011 \mathrm{~g} ; 68$.

3. Hamroeva ZD. Ocenka klinicheskogo techeniya i osobennostej lecheniya osteoartroza u lic pozhilogo i starcheskogo vozrasta. [dissertacya]. Dushanbe, 2016

4. Curko W, Egorov IV, Krasnoselskij MYA. Sustavnoj sindrom u pozhilyh: Patofi-ziologiya boli i kliniko-vozrastnye aspekty terapii. Consilium Medicum. 2009; 11 (2): 2-10.

5. Shukurova SM, Hamroeva ZD, SHodiev BR. Osteoartroz kak vazhnaya problema geriatrii. Vestnik Avicenny. 2015; (1): 137-143.

6. Vignon E, Valat JP, Rossignol M, et al. Osteoarthritis of the knee and hip and activity: a systematic international review and synthesis (OASIS). Joint Bone Spine. 2006; (73): 442-55.

7. Alekseeva LI, Cvetkova ES. Osteoartroz: iz proshlogo v budushchee. Nauchno-prakticheskaya revmatologiya. 2009; (2): 31-39.

8. Batpenov ND, Bajmagambetov ShA i dr. Artroskopiya kolennogo sustava pri osteoart-roze kolennogo sustava. Materialy VII Kongressa Rossijskogo artroskopicheskogo obshchestva. M., 2007; 49.

9. Dubrov VEh, Yarema IV, Rebrov VN. Kompleksnoe lechenie degenerativno-vospalitel'nyh porazhenij kolennogo sustava u pozhilyh bol'nyh. Travmatologiya i ortopediya Rossii. 2005; (35): 49. эндопротезированию при гонартрозах [диссертация] М., 2013.

15. Тихилов Р. М., Шубняков И. И., Коваленко А. Н. и др. Данные регистра эндопротезирования тазобедренного сустава РНИИТО им. Р. Р. Вредена за 2007-2012 годы. Травматология и ортопедия России. 2013; (3): 167-90.

16. Середа А. П., Грицюк А. А., Зеленяк К. Б., Серебряков А. Б. Факторы риска инфекционных осложнений после эндопротезирования коленного сустава. Инсекции в хирургии. 2010; 8 (4): 67-76.

17. Gioe TJ, Killeen KK, Grimm K, et al. Why are total knee replacements revised? Analysis of early revision in a community knee implant registry. Clin Orthop Relat Res. 2004; (428): 100-6.

18. Лычагин А. В. Хирургическое лечение структурно-функциональных нарушений при гонартрозе [диссертация]. М., 2017.

10. Zabolotnyh II, Zabolotnyh VA. Bolezni sustavov v pozhilom vozraste. SPb.: "Petropolis", 2000; 144.

11. Karateev DE. Farmakoterapiya osteoartroza: ehffektivnost' i bezopasnost'. Poliklinika. 2010; (5): 74-9.

12. Sinusas K. Osteoarthritis: diagnosis and treatment. Am Fam Physician. 2012; 85 (1): 49-56.

13. Kavalerskij GM, Lychagin AV, Smetanin SM i dr. Istoricheskoe razvitie koncepcii ehndoprotezirovaniya kolennogo sustava. Kafedra travmatologii i ortopedii. 2016; (3): 16-20.

14. Tarbushkin AA. Ocenka strukturno-funkcional'nyh narushenij kolennogo sustava dlya opredeleniya pokazaniya $k$ ehndoprotezirovaniyu pri gonartrozah [dissertaciya]. M., 2013.

15. Tihilov RM, Shubnyakov II, Kovalenko AN i dr. Dannye registra ehndoprotezirovaniya tazobedrennogo sustava RNIITO im. R. R. Vredena za 2007-2012 gody. Travmatologiya i ortopediya Rossii. 2013; (3): 167-90.

16. Sereda AP, Gricyuk AA, Zelenyak KB, Serebryakov AB. Faktory riska infekcionnyh oslozhnenij posle ehndoprotezirovaniya kolennogo sustava. Infekcii v hirurgii. 2010; 8 (4): 67-76.

17. Gioe TJ, Killeen KK, Grimm K, et al. Why are total knee replacements revised? Analysis of early revision in a community knee implant registry. Clin Orthop Relat Res. 2004; (428): 100-6.

18. Lychagin AV. Hirurgicheskoe lechenie strukturno-funkcional'nyh narushenij pri gonartroze [dissertaciya]. M., 2017. 